\title{
Writers bear witness to those living on the edge
}

\author{
Writing on the Edge: Great Contemporary \\ Writers on the Front Line of Crisis \\ Tom Craig \\ Dan Crowe, Editor \\ Rozzoli International Publications, Inc.; \\ 2010.
}

$\mathrm{W}$ riting on the Edge is the brainchild of Tom Craig, a photographer whose work has taken him to places where human suffering and misery are present in epic scale. Having witnessed so much adversity, much of it manmade, he felt he could no longer keep silent, and needed "to yell to everyone ... that they must, at the very least, hear about [it,]" so that his compatriots would be shaken out of their complacency, even if only briefly.

And so, he set about enlisting 14 well-known writers and film people to bear witness to the tragedies unfolding in some of the many hot spots around the globe. The common thread linking all of them is the work of medical and logistical personnel from nongovernmental organizations in caring for the sick, the wounded and the starving, in spite of the indifference and often overt hostility of local governments and militias.

The list of contributors is remarkable, as is the calibre of their writing. Whether describing the horrors of war and gang violence, attempts to locate the relatives of refugees from Azerbaijan or training local providers at a new AIDS clinic in Russia, the reader's eyes are opened to just how many people's lives conform to Hobbes' description of the natural state of mankind as "solitary, poor, nasty, brutish, and short." And without the efforts of those who dare to challenge the current state of affairs, their plight might be far worse.

Tracy Chevalier, in writing about Burundi, describes conversations with women about their children in which "they tell me how many boys and girls [they have], but there is always a

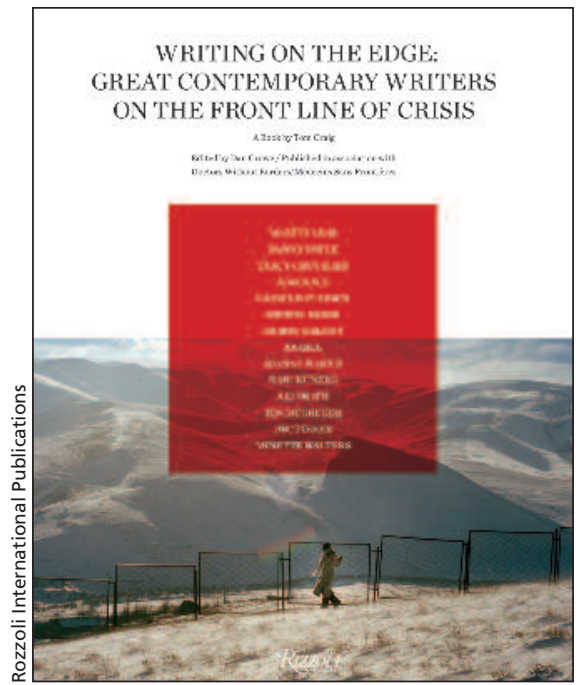

ghostly third number lurking behind the others, the number of children who died of the usual killers: cholera, malaria, typhoid, malnutrition." Martin Amis, writing about the gang violence in the Aguablanca quarter of the city of Cali, Columbia describes the socioeconomic forces that led to its inhabitants being displaced from their original homes and the resulting tensions in the impoverished barrios which erupt into lethal violence between the hundreds of gangs who take advantage of the cheap and abundant weapons. Noting that "the classic venganza in Cali gangland is not a bullet through the head but a bullet through the spine," Amis interviews a physical therapist working with these paralyzed and impotent young men and describes heartbreakingly how the men gradually become aware of the awful permanence of their disabilities.

Craig's photographs, accompanying each of the 14 chapters, makes the text come alive. The suffering described, after all, cannot be accurately captured by numbers and statistics alone; what is needed is a face, a glance, a gesture. The fact that infant mortality in Sierra Leone is so high, that one in three children there dies before the fifth birthday is horrible enough. But one begins to really grasp its significance through the picture of the young woman in a refugee camp in Chad lying alongside her newborn twins who are slowly starving to death. And it is her story, told by A.A. Gill, which continues to haunt long after the reader has finished the book. This young mother had initially decided not to nurse her babies, for reasons that are never made clear, leaving the author and the reader to speculate as to what could bring a new mother to turn away from her children and let them starve to death. Was this an expression of hopelessness at their chances of survival in the harsh environment they were born into? Or of her hope for a better chance of her own survival untrammeled by the burden of two additional mouths to feed? Was the pregnancy unwanted, perhaps the product of rape? Her eyes, face and posture reflect her stubbornness mingled with stoic resignation, yet cannot hide the pain she so clearly feels. While we learn at the end of the chapter that she decided to start nursing them after several days of refusing to, the questions remain, unanswered and troubling.

This is a moving book, one which weaves anger and horror at the misery endured by so many with admiration for the efforts of some to try and mitigate or even reverse it. Pondering over what she had seen in Brazzaville, Congo, Joanne Harris writes "it's hard to leave; it's as if something in this place has got into my blood. ... Maybe this is why people risk their lives to work for MSF [Médicins Sans Frontières], to live on a tiny salary, in primitive conditions far from their families, all the while knowing that one individual can never, ever do enough, but doing it anyway, quietly, in hope."

\section{Dennis Rosen MD \\ Division of Respiratory Diseases \\ Children's Hospital Boston \\ Harvard Medical School \\ Boston, Mass.}

CMAJ 2011. DOI:10.1503/cmaj.101521 